BMJ Open

Diabetes

Research

\& Care

\title{
Quality gaps in screening and monitoring for postoperative hyperglycemia in a Canadian hospital: a retrospective cohort study
}

\author{
Shannon M Ruzycki (D) , ${ }^{1,2}$ Tyrone G Harrison, ${ }^{1,2}$ Edwin Enns, ${ }^{1}$ Julie McKeen, ${ }^{1}$ \\ Karmon Helmle (D) , ${ }^{1}$ Anna Cameron ${ }^{3}$
}

To cite: Ruzycki SM, Harrison TG, Enns E, et al. Quality gaps in screening and monitoring for postoperative hyperglycemia in a Canadian hospital: a retrospective cohort study. BMJ Open Diab Res Care 2021;9:e002445. doi:10.1136/ bmjdrc-2021-002445

Received 18 June 2021 Accepted 18 September 2021

Check for updates

(c) Author(s) (or their employer(s)) 2021. Re-use permitted under CC BY-NC. No commercial re-use. See rights and permissions. Published by BMJ.

${ }^{1}$ Department of Medicine, University of Calgary, Calgary, Alberta, Canada

${ }^{2}$ Department of Community Health Sciences, University of Calgary, Calgary, Alberta, Canada

${ }^{3}$ Department of Obstetrics and Gynecology, Cumming School of Medicine, Calgary, Alberta, Canada

Correspondence to Dr Shannon M Ruzycki; shannon.ruzycki@ucalgary.ca

\section{ABSTRACT}

Introduction Evidence-based preoperative, intraoperative and postoperative glycemic management may reduce poor surgical outcomes. Previous studies suggest that quality gaps in perioperative glycemic management may be common.

Research design and methods This retrospective cohort study used administrative health and laboratory data from a single center to estimate quality gaps in perioperative glycemic management in patients with and without diabetes between April 2019 and March 2020. We examined the proportion of patients with preoperative hemoglobin $\mathrm{A} 1 \mathrm{c}(\mathrm{HbA1c})$ measurement, postoperative point-of-care testing (POCT) for glucose, hyperglycemia, and basal bolus insulin regimens. We compared the median length of stay (LOS) in patients with and without postoperative hyperglycemia, adjusted for age and sex. Results There were 6576 patients in our cohort; 1165 (17.8\%) had diabetes. Most patients with diabetes had an $\mathrm{HbA1c}$ measured prior to surgery $(\mathrm{n}=697,59.8 \%)$. Postoperatively, $16.9 \%$ of patients with diabetes had no POCT monitoring $(n=197)$ and $65.7 \%$ had hyperglycemia $(n=636)$. Only $35.9 \%$ of patients who received insulin had a basal bolus insulin regimen $(n=229)$. Patients with diabetes who had postoperative hyperglycemia had a longer median LOS compared with those who did not have postoperative hyperglycemia ( 8.4 days ( $95 \% \mathrm{Cl} 7.5$ to 9.4 ) and 6.7 days ( $95 \% \mathrm{Cl} 6.3$ to 7.1$)$, respectively). In patients without diabetes, median LOS was 7.4 days $(95 \% \mathrm{Cl} 4.4$ to 10.4) for those with hyperglycemia and 5.2 days $(95 \% \mathrm{Cl}$ 5.1 to 5.4) for those with in-target glucose.

Conclusions Quality gaps in perioperative glycemic management include measurement of blood glucose after surgery and treatment of postoperative hyperglycemia. These gaps may contribute to longer LOS.

\section{INTRODUCTION}

Patients with postoperative hyperglycemia have worse outcomes compared with patients with euglycemia, including increased length of stay (LOS), greater need for intensive care, more frequent hospital readmission, and more frequent infections. ${ }^{1-5}$ Patients with postoperative glucose measurements even $1.0 \mathrm{mmol} / \mathrm{L}$ above target have an absolute

\section{Significance of this study}

What is already known about this subject?

- Postoperative hyperglycemia is associated with worse outcomes for patients with and without diabetes.

What are the new findings?

- We identified important quality gaps in perioperative glycemic management at our center.

- Forty percent of patients were not screened for risk of postoperative hyperglycemia before surgery.

- Seventeen percent of patients with known diabetes had no measurement of blood glucose after surgery and two-thirds had hyperglycemia.

- Patients with and without diabetes who had hyperglycemia had a longer length of stay than patients without hyperglycemia.

How might these results change the focus of research or clinical practice?

- Altogether, these results highlight the need for theory-informed knowledge translation strategies to improve perioperative glycemic management.

30-day mortality risk that is $0.6 \%$ higher than patients who are within target. ${ }^{6}$ In addition, patients with postoperative hyperglycemia have $6 \%$ more infections than patients with euglycemia. ${ }^{67}$

While patients with diabetes are at greatest risk of postoperative hyperglycemia, an additional $5 \%-10 \%$ of patients without diabetes also experience postoperative hyperglycemia ${ }^{8}$ and an estimated $10 \%$ of patients have unrecognized diabetes. ${ }^{2}$ Since diabetes affects $20 \%-30 \%$ of surgical patients, ${ }^{9}$ a conservative estimate is that $25 \%-35 \%$ of surgical patients are at risk of postoperative hyperglycemia.

Evidence-based and guideline-informed perioperative glycemic management has reduced LOS and surgical site infections; $;^{10-12}$ however, implementation of best practices 


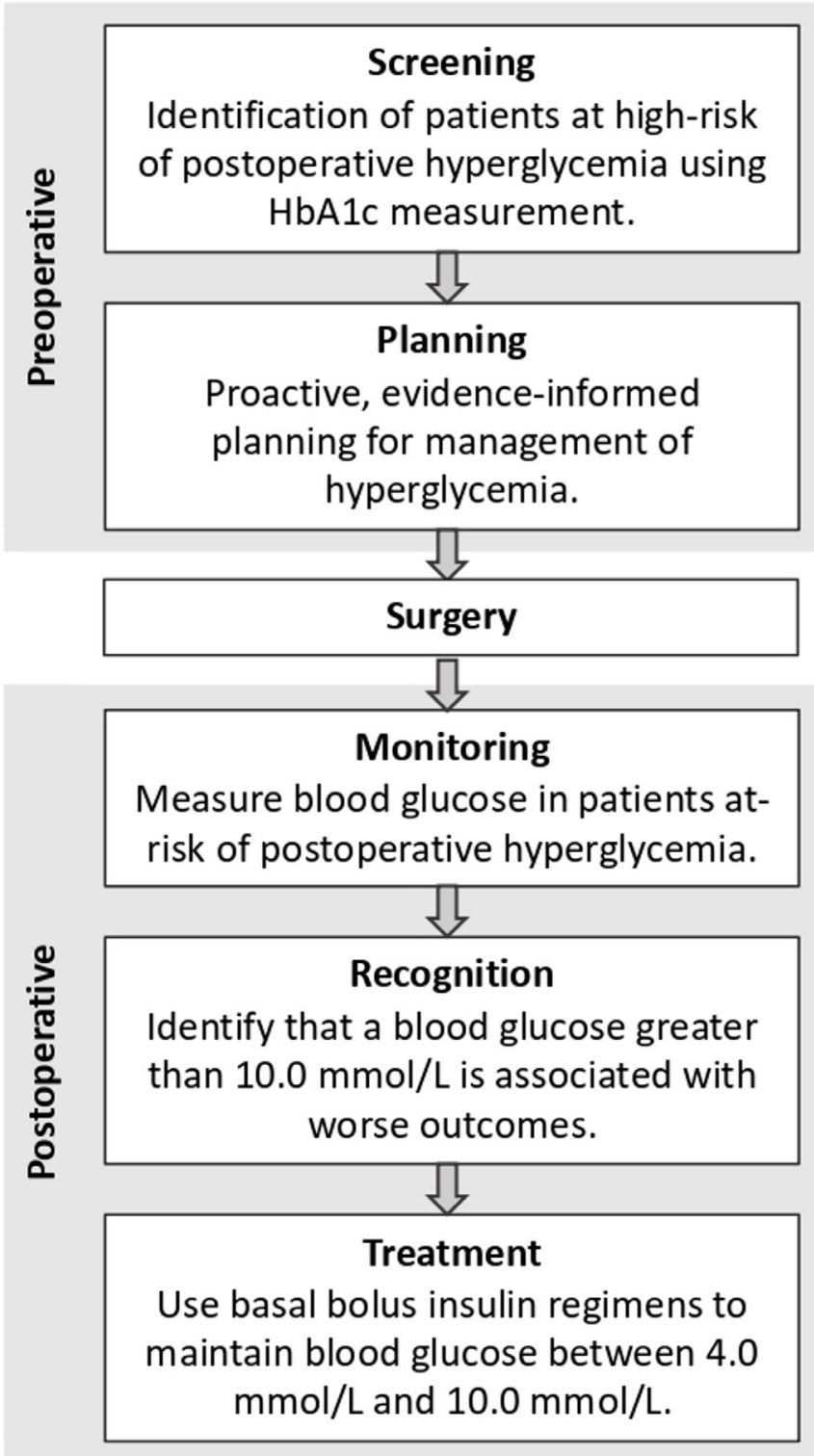

Figure 1 Process map detailing perioperative glycemic management. $\mathrm{HbA1c}$, hemoglobin A1c.

for glycemic management is challenging. ${ }^{13}$ Implementation in the perioperative period is further complicated by the need to coordinate clinical care between multiple medical specialists (eg, surgeons, internal medicine, anesthesia) and settings (eg, the preoperative outpatient surgical appointment, preoperative outpatient internal medicine appointment, and the inpatient surgical hospitalization). Successful perioperative glycemic pathways are multidisciplinary and require significant stakeholder engagement. ${ }^{1011}$

We have previously reported a framework for understanding and evaluating perioperative glycemic management (figure 1). ${ }^{14}$ This framework requires: (1) preoperative screening for risk of postoperative hyperglycemia based on hemoglobin A1c (HbA1c) results; (2) proactive planning for patients at risk of postoperative hyperglycemia; (3) postoperative monitoring for hyperglycemia using capillary glucose point-of-care testing (POCT); (4) recognition of postoperative hyperglycemia; and (5) appropriate treatment of postoperative hyperglycemia.

Previous quality improvement work by our study team and other groups suggests that there are important quality gaps in perioperative management of hyperglycemia. ${ }^{15-17}$ In the UK, nearly $50 \%$ of patients with diabetes undergoing surgery did not have any blood glucose measurements intraoperatively and $14 \%$ had no measurements in the immediate recovery room. ${ }^{15}$ In our center, fewer than half of patients with diabetes who were seen by an internal medicine physician before surgery had recommendations for postoperative glycemic management. ${ }^{16}$ Further, we found that surgical team members reported low perceived skills for recognizing and managing postoperative hyperglycemia. ${ }^{16}$ Therefore, the objective of this current study was to evaluate current screening, monitoring, and treatment for patients with and without diabetes in our setting to identify potential quality gaps. Our secondary objective was to estimate the association between postoperative hyperglycemia and LOS.

\section{RESEARCH DESIGN AND METHODS Study design}

This retrospective cohort study used electronic health record (EHR) data to measure process, outcome, and balancing measures tied to a previously described framework for perioperative glycemic management ${ }^{14}$ to assess the quality of perioperative diabetes management in a single hospital system. ${ }^{18}$ This manuscript is reported according to the Reporting of Studies Conducted Using Observational Routinely Collected Health Data exten$\operatorname{sion}^{19}$ of the Strengthening the Reporting of Observational Studies in Epidemiology guidelines ${ }^{20}$ and the Strengthening the Reporting of Cohort Studies in Surgery guideline. ${ }^{21}$

\section{Setting}

The cohort was derived of patients undergoing noncardiac surgery at a quaternary acute care academic hospital in Canada with a catchment area over more than 2 million people. Endocrinology and internal medicine consultation services are available 24 hours/day, every day. This hospital uses an EHR (Sunrise Clinical Manager; Allscripts, Richmond, British Columbia, Canada) that houses all admission, LOS, point-of-care capillary glucose data, and inpatient laboratory results. All outpatient laboratory results that are performed in our province are contained in a separate information system (Netcare; Alberta Health and Wellness) which is integrated into the inpatient EHR. Comorbidity data for each hospitalization are recorded using the Tenth Revision of International Statistical Classification of Diseases and Related Health Problems codes that have been modified for Canadian use, found in the discharge abstract database (DAD). Procedure codes based on the Canadian Classification of 
Health Interventions are housed in Picis patient management software (Wakefield, Massachusetts). Data from the EHR were linked to the DAD and the provincial outpatient laboratory database. Personal healthcare numbers were used to create person-level, deterministic linkages across the various databases accessed. Over 99\% of Albertans are enrolled in free comprehensive health insurance and health services are publicly administered. Hence, outpatient data including labs are nearly completely captured for use in health studies such as ours.

\section{Population}

We included adults 18 years and older who underwent non-cardiac surgery at our hospital and were admitted for more than 24 hours after surgery between 1 April 2019 and 30 March 2020. Patients were pragmatically categorized as having diabetes if they had a diagnosis of diabetes in the $\mathrm{DAD}^{22} 23$ or an outpatient HbAlc greater than $6.5 \%(48 \mathrm{mmol} / \mathrm{mol})$ in the year before surgery or during the surgical admission. ${ }^{24}$ Patients were considered to not have diabetes if they had an HbAlc in the year before surgery or during the surgical admission that was less than $6.4 \%$ (46 mmol $/ \mathrm{mol})$ and no diagnosis of diabetes in the DAD. ${ }^{24}$ Patients had an unknown diabetes status if they had no diagnosis of diabetes in the DAD and no HbAlc in the year before surgery or during the surgical admission. The exposure of interest in this study for the analysis of LOS was diabetes diagnosis.

Surgical urgency was determined by the surgeon and extracted from the request for surgical booking. Emergent surgeries are scheduled within 24 hours of the request, urgent surgeries are scheduled between 3 days and 6 weeks from the request, and elective surgeries are booked at any available time from the request.

\section{Outcomes}

Outcomes were defined using the perioperative glycemic process map developed with input from endocrinologists, perioperative internists, surgeons, data analysts, and quality improvement experts (figure 1). ${ }^{14}$ Measures are reported separately for patients with and without diabetes, and are stratified into screening measures, perioperative monitoring measures, perioperative glycemic outcome measures, and balancing measures. All measures are reported for the first 24 hours after surgery, which is based on previous work that suggests this is the most critical time period for development of adverse postoperative complications due to hyperglycemia. ${ }^{6}$ We defined in-target point-ofcare capillary glucose measurement using the Diabetes Canada target as between 4.0 and $10.0 \mathrm{mmol} / \mathrm{L}^{25} \mathrm{We}$ measured the proportion of high-risk patients who underwent preoperative HbAlc measurement within the year prior to surgery or during the surgical admission. Monitoring for postoperative hyperglycemia was based on the number of POCT measurements in the first 24 hours after surgery. There are no major society guideline recommendations on the optimal number of POCT measurements after surgery, ${ }^{26}$ but our institutional policies recommend four times per day for patients using insulin or with diabetes and fasting. ${ }^{27}$

Outcome measures included the proportion of POCT per patient that were in target, and number of patients with moderate (one or more POCT results between 14.0 and $17.9 \mathrm{mmol} / \mathrm{L}$ ) or severe hyperglycemia (one or more POCT results $>18.0 \mathrm{mmol} / \mathrm{L}$ ), considering only patients who had at least one POCT measurement. The balancing measure was the number of patients who experienced a hypoglycemic episode (one or more POCT results $<4.0 \mathrm{mmol} / \mathrm{L})$.

Patients were categorized as having received a sliding scale insulin regimen (also called variable dose subcutaneous insulin regimen or correction-only dose insulin) if they received correction dose insulin alone without scheduled mealtime (if not nil per os (NPO)) or basal insulin for more than $65 \%$ of their inpatient stay. Patients were considered to have received a basal bolus insulin regimen if they received an ultra-long-acting, long-acting, or intermediate-acting insulin formulation and a scheduled mealtime insulin (if eating) dose for more than $65 \%$ of their inpatient stay. Intravenous insulin is only used during metabolic decompensation or in critical care units in our hospital and is not routinely used for the perioperative setting. ${ }^{26}$ Length of hospital stay in days was extracted from the EHR.

\section{Statistical analysis}

Statistical analyses were performed using Stata software V.16.0 (StataCorp), using two-sided statistical significance $(\mathrm{p}<0.05)$. Baseline characteristics are summarized for the overall cohort and for patients with and without diabetes and patients with no HbAlc measurement in the 1 year before surgery. We report counts and percentages for categorical variables and medians with IQRs for non-parametric continuous variables. For our exploratory outcome of LOS, we used quantile regression to estimate age and sex-adjusted LOS (and accompanying $95 \%$ CIs). We used a four-level categorical exposure in this analysis to compare patients with and without diabetes who had and did not have postoperative hyperglycemia: (1) diabetes and hyperglycemia, (2) diabetes and no hyperglycemia, (3) no diabetes and hyperglycemia, and (4) no diabetes and no hyperglycemia.

\section{RESULTS}

There were 6576 patients who met the inclusion criteria during the study period. The median age was 64 years (IQR 55-72 years) and $55.8 \%$ were female $(\mathrm{n}=3671)$. The median postoperative LOS was 5 days (IQR 2-11 days) and most surgeries were categorized as urgent $(n=3011,45.8 \%)$ (table 1$)$. Less than half of all patients had a recent HbAlc measurement $(41.8 \%$, $\mathrm{n}=2746$ ), including $59.8 \%$ of patients with diabetes $(n=697)$. 
Table 1 Cohort characteristics by diabetes status

\begin{tabular}{lllll}
\hline & Total cohort & Diabetes & No diabetes* & No HbA1c measurement \\
\hline $\mathrm{n}(\%)$ & 6576 & $1165(17.8)$ & $2049(31.2)$ & $3362(51.1)$ \\
\hline Female & $3671(55.8)$ & $548(47.0)$ & $1318(64.3)$ & $1805(53.7)$ \\
\hline Age & $64(55-72)$ & $67(59.5-74)$ & $63(54-71)$ & $63(54-73)$ \\
Had an HbA1c in the past 12 months (n, \%) & $2746(41.8)$ & $697(59.8)$ & $2049(100.0)$ & 0 \\
HbA1c (\%, median (IQR)) & $5.8(5.5-6.2)$ & $7.0(6.5-7.9)$ & $5.6(5.4-5.9)$ & - \\
Unadjusted length of stay (days, median (IQR)) & $5(2-11)$ & $6(3-14)$ & $3(2-6)$ & $5(2-11)$ \\
Surgery category & & & & $967(26.8)$ \\
$\quad$ Elective & $2217(33.7)$ & $314(19.9)$ & $668(34.0)$ & $1479(41.2)$ \\
$\quad$ Urgent & $3011(45.8)$ & $993(63.0)$ & $6(0.0)$ & $1146(31.9)$ \\
\hline Emergent & $1343(20.4)$ & $268(17.0)$ & $1286(65.5)$ & \\
\hline
\end{tabular}

${ }^{*} \mathrm{HbA} 1 \mathrm{c}<6.5 \%$ and no diagnosis of diabetes in the discharge abstract database (DAD).

$\mathrm{HbA1c}$, hemoglobin A1c.

Patients with diabetes

Of the entire cohort, $1165(17.8 \%)$ had diabetes. The median preoperative HbAlc for these patients was $7.0 \%(53 \mathrm{mmol} / \mathrm{mol}$; IQR $6.5 \%-7.9 \%)$ (table 1$)$. After surgery, $16.9 \%$ of these patients with diabetes had no
POCT measurements $(\mathrm{n}=197)$ (table 2). Of patients with diabetes who had at least one POCT measurement after surgery, $65.7 \%$ had hyperglycemia $(\mathrm{n}=636)$ and $16.9 \%$ and $5.1 \%$ experienced moderate and severe hyperglycemia, respectively, in the first 24 hours after surgery.

Table 2 Adherence of patients to perioperative glycemic management strategies and clinical outcomes for patients with and without diabetes

\begin{tabular}{|c|c|c|c|}
\hline & Diabetes* & No diabetes† & Unknown diabetes status \\
\hline $\mathrm{n}(\%)$ & $1165(17.8)$ & $2049(31.2)$ & $3362(51.1)$ \\
\hline \multicolumn{4}{|l|}{ Screening } \\
\hline Had an $\mathrm{HbA1c}$ in the past 12 months (n, \%) & $697(59.8)$ & $2049(100.0)$ & 0 \\
\hline \multicolumn{4}{|l|}{ Monitoring } \\
\hline Median number of POCT measurements per patient (IQR) & $4(2-5)$ & $0(0-0)$ & $0(0-0)$ \\
\hline Patients with no POCT measurements (\%) & $197(16.9)$ & $1841(89.9)$ & $3115(92.7)$ \\
\hline \multicolumn{4}{|l|}{ Glycemic outcomes } \\
\hline No in-target POCT measurements $\ddagger \S(\%)$ & $192(19.8)$ & $6(2.9)$ & $20(8.1)$ \\
\hline All POCT measurements in target $\$ \S(\%)$ & $331(34.2)$ & $166(79.8)$ & $172(70.4)$ \\
\hline Any hyperglycemiał§ (\%) & $636(65.7)$ & $38(18.3)$ & $69(27.9)$ \\
\hline Moderate hyperglycemiał§ (\%) & $140(16.9)$ & $1(0.5)$ & $5(2.1)$ \\
\hline Severe hyperglycemiał§ (\%) & $47(5.1)$ & 0 & $3(1.2)$ \\
\hline An episode of hypoglycemia $\ddagger$ (\%) & $28(2.9)$ & $6(2.9)$ & $8(2.9)$ \\
\hline \multicolumn{4}{|l|}{ Recognition and treatment } \\
\hline Received insulin in hospital & $638(55.8)$ & $24(1.2)$ & $69(2.1)$ \\
\hline Any hyperglycemia & $458(72.0)$ & $9(23.7)$ & $31(44.9)$ \\
\hline Moderate hyperglycemia & $117(83.6)$ & $1(100.0)$ & $4(80.0)$ \\
\hline Severe hyperglycemia & $42(89.4)$ & - & $3(100.0)$ \\
\hline \multicolumn{4}{|l|}{ Regimen } \\
\hline Sliding scale correction-only regimen & $409(64.1)$ & $10(76.9)$ & $50(82.0)$ \\
\hline Basal bolus insulin regimen & 229 (35.9) & $3(23.1)$ & $11(18.0)$ \\
\hline
\end{tabular}

${ }^{*} \mathrm{DAD}$ diagnosis or $\mathrm{HbA} 1 \mathrm{c} \geq 6.5 \%$.

†No DAD diagnosis and $\mathrm{HbA} 1 \mathrm{c}<6.5 \%$.

¥Of patients with any POCT.

§Capillary glucose between 4.0 and $10.0 \mathrm{mmol} / \mathrm{L}$ is considered within target; moderate hyperglycemia is $14.0-17.9 \mathrm{mmol} / \mathrm{L}$; severe hyperglycemia is $\geq 18.0 \mathrm{mmol} / \mathrm{L}$.

$\mathrm{DAD}$, discharge abstract database; HbA1c, hemoglobin A1c; POCT, point-of-care testing. 
Table 3 Hyperglycemia in patients with diabetes by surgical service for patients who had at least one capillary glucose measurement (POCT)

\begin{tabular}{lllllll}
\hline & & \multicolumn{7}{c}{ Patients with diabetes } & & \\
\cline { 3 - 7 } Surgical type & Total cohort & Total & $\begin{array}{l}\text { Ane POCT } \\
\text { measurement }\end{array}$ & $\begin{array}{l}\text { Any } \\
\text { hyperglycemia }\end{array}$ & $\begin{array}{l}\text { Moderate } \\
\text { hyperglycemia }\end{array}$ & $\begin{array}{l}\text { Severe } \\
\text { hyperglycemia }\end{array}$ \\
\hline All patients & 6576 & 1165 & $965(82.8)$ & $633(65.7)$ & $140(16.9)$ & $47(5.1)$ \\
Gastrointestinal & $1(0.0)$ & 0 & - & - & - & - \\
\hline General surgery & $1336(20.3)$ & $240(20.6)$ & $198(82.5)$ & $142(59.2)$ & $34(14.2)$ & $12(5.0)$ \\
\hline Gynecology & $930(14.1)$ & $141(12.1)$ & $122(86.5)$ & $87(61.7)$ & $18(12.8)$ & $3(2.1)$ \\
\hline Neurosurgery & $625(9.5)$ & $84(7.2)$ & $73(86.9)$ & $39(46.4)$ & $12(14.3)$ & $2(2.4)$ \\
\hline Ophthalmology & $2(0.0)$ & 0 & - & - & - & - \\
\hline Oral maxillofacial & $1(0.0)$ & 0 & - & - & - & - \\
\hline Orthopedic surgery & $1427(21.7)$ & $263(22.6)$ & $215(81.1)$ & $134(50.6)$ & $21(7.9)$ & $11(4.2)$ \\
\hline Otolaryngology & $179(2.7)$ & $33(2.8)$ & $17(51.5)$ & $12(36.4)$ & $3(9.1)$ & $1(3.3)$ \\
\hline Plastic surgery & $186(2.8)$ & $32(2.8)$ & $30(90.9)$ & $19(57.6)$ & $4(12.1)$ & $2(6.1)$ \\
\hline Radiology & $4(0.1)$ & 0 & - & - & - & - \\
\hline Spine surgery & $856(13.0)$ & $138(11.9)$ & $117(84.5)$ & $68(28.6)$ & $14(10.1)$ & $2(1.4)$ \\
\hline Thoracic surgery & $370(5.6)$ & $50(4.3)$ & $40(80.0)$ & $32(64.0)$ & $7(14.0)$ & $2(4.0)$ \\
\hline Transplant & $126(1.9)$ & $52(4.5)$ & $48(92.3)$ & $40(76.9)$ & $15(28.8)$ & $10(19.2)$ \\
\hline Urology & $21(0.3)$ & $4(0.3)$ & $1(25.0)$ & $1(25.0)$ & 0 & 0 \\
\hline Vascular & $512(7.8)$ & $128(11.0)$ & $104(81.3)$ & $59(46.1)$ & $12(42.9)$ & $2(1.6)$ \\
\hline
\end{tabular}

Capillary glucose between 4.0 and $10.0 \mathrm{mmol} / \mathrm{L}$ is considered within target; moderate hyperglycemia is $14.0-17.9 \mathrm{mmol} / \mathrm{L}$; severe hyperglycemia is $\geq 18.0 \mathrm{mmol} / \mathrm{L}$.

POCT, point-of-care testing.

Nearly one in five patients with diabetes had no POCT measurements that were in target $(4.0-10.0 \mathrm{mmol} / \mathrm{L})$. Only $72.0 \%$ of patients with diabetes who had hyperglycemia received insulin during their admission and nearly $11 \%$ of patients with severe hyperglycemia did not receive insulin. Only $35.9 \%$ of patients with diabetes who received insulin in hospital received treatment with a basal bolus insulin regimen $(n=229)$ and $64.1 \%$ received a sliding scale-only regimen $(n=409)$. The proportion of patients with diabetes who received at least one POCT after surgery and who had postoperative hyperglycemia varied by surgical service (table 3 ).

\section{Patients without diabetes}

There were 2049 patients without diabetes, as defined by HbAlc less than $6.4 \%,{ }^{24}$ and no diagnosis of diabetes recorded in the DAD (31.2\%). Most of these patients had no monitoring for hyperglycemia after surgery (table 2). Of patients with at least one POCT measurement after surgery, hyperglycemia occurred in $18.3 \% \quad(\mathrm{n}=38 / 208)$ and most was mild (POCT $10.0-13.9 \mathrm{mmol} / \mathrm{L}$ ). Less than half of patients with hyperglycemia received insulin and sliding scale-only regimens were more common than basal bolus insulin regimens.

\section{Patients with unknown diabetes status}

Nearly half of all patients had an unknown diabetes status $(\mathrm{n}=3362,51.1 \%)$ (table 2). Most of these patients had no
POCT measurements in the first 24 hours after surgery $(\mathrm{n}=3115,92.7 \%)$. Of the patients with an unknown diabetes status who had at least one POCT measurement, $27.9 \%$ had hyperglycemia $(n=69 / 247)$, and $2.1 \%$ and $1.2 \%$ had moderate and severe hyperglycemia, respectively. Sliding scale-only insulin regimens were again more common than basal bolus insulin regimens.

\section{Hospital LOS}

Patients with diabetes who had postoperative hyperglycemia had a higher median-adjusted LOS of 8.4 days (95\% CI 7.5 to 9.4) when compared with patients with diabetes who did not have postoperative hyperglycemia with a median LOS of 6.7 days (95\% CI 6.3 to 7.1). In patients without diabetes, the median LOS for patients with postoperative hyperglycemia was 7.4 days $(95 \%$ CI 4.4 to 10.4 ) and for patients without postoperative hyperglycemia it was 5.2 days (95\% CI 5.1 to 5.4 ) (table 4 ).

\section{CONCLUSIONS}

This large retrospective cohort study identified important quality gaps in perioperative glycemic management and reports an exploratory association of postoperative hyperglycemia with increased LOS in patients with and without postoperative hyperglycemia. In particular, we report inadequate monitoring for and treatment of postoperative hyperglycemia in patients with diabetes. 
Table 4 Median-adjusted ${ }^{*}$ length of stay $(95 \% \mathrm{Cl})$ for patients with and without diabetes who had postoperative hyperglycemia

\begin{tabular}{lll}
\hline & $\begin{array}{l}\text { Postoperative } \\
\text { hyperglycemia } \\
\text { (>10.0 mmol/L) }\end{array}$ & $\begin{array}{l}\text { No postoperative } \\
\text { hyperglycemia } \\
\text { (<10.0 mmol/L) }\end{array}$ \\
\hline Diabetes & $8.4(7.5-9.4)$ & $6.7(6.3-7.1)$ \\
No diabetes & $7.4(4.4-10.4)$ & $5.2(5.1-5.4)$ \\
\hline
\end{tabular}

${ }^{*}$ Adjusted for sex and age at the time of the procedure.

Postoperative hyperglycemia was common; the proportion of patients with postoperative hyperglycemia ranged from 1 in 6 for patients without diabetes to 2 in 3 for patients with known diabetes. In our setting, patients with hyperglycemia had an estimated LOS that was 1.7 days longer for patients with diabetes and 2.2 days for patients without known diabetes. Altogether, these data suggest important quality gaps in perioperative glycemic management from screening patients for diabetes to appropriate treatment of patients with hyperglycemia.

In our study, $42 \%$ of patients had no recent $\mathrm{HbAlc}$ measurement. This is similar to other settings, where about half of patients with diabetes underwent preoperative HbAlc measurement. ${ }^{15} 28$ While Diabetes Canada does not recommend preoperative screening for diabetes, expert panels and other major society guidelines suggest universal $\mathrm{HbAlc}$ measurement for patients with diabetes undergoing surgery. ${ }^{172930}$ Studies with universal preoperative measurement of $\mathrm{HbA1c}$ for all patients undergoing surgery estimate that $4 \%-11 \%$ of patients have unrecognized diabetes. ${ }^{2} 3132$ In addition, preoperative HbAlc is a strong predictor of postoperative hyperglycemia, even in patients without diabetes. ${ }^{6}$ A large observational study by Jones et al found that patients with known diabetes were more likely to undergo monitoring for postoperative hyperglycemia and were more likely to receive appropriate treatment for hyperglycemia than patients with postoperative hyperglycemia who did not have diabetes. ${ }^{2}$ Similarly, a UK-based study found that intraoperative and postoperative glucose testing was more commonly performed for patients with diabetes when their diagnosis of diabetes was included on the surgical safety checklist. ${ }^{15}$ Altogether, this evidence suggests that preoperatively identifying patients with abnormal HbAlc may improve quality of care. At minimum, surgical patients who qualify for diabetes screening based on risk factors such as age, family history, or obesity should undergo HbA1c measurement. ${ }^{33}$

While most major society guidelines do not comment on the optimal number of POCT after surgery for patients with diabetes, ${ }^{2530}$ previous evidence suggests that patients who undergo increased POCT have improved outcomes, including fewer hospital readmissions within 30 days. ${ }^{2}$ We report that $17 \%$ of patients with diabetes had no POCT measurement in the first 24 hours after surgery. Due to these low rates of postoperative POCT in patients with diabetes, we cannot estimate the true burden of hyperglycemia in our setting; however, at minimum, $55 \%$ of patients with diabetes in our study had at least one episode of hyperglycemia. This is lower than other centers, which found that about $90 \%$ of postoperative patients with diabetes had hyperglycemia. ${ }^{34} 35$

Glucose measurement was infrequently performed in patients without known diabetes, and thus we cannot reliably estimate the proportion of these patients who had hyperglycemia. There were $28 \%$ of patients with unknown diabetes status and $18 \%$ of patients without diabetes who had postoperative hyperglycemia; however, this may be overestimated due to indication bias. Studies that performed POCT in all surgical patients identified postoperative hyperglycemia in $20 \%^{1535}$ to $60 \%{ }^{32} 3637$ of patients without known diabetes. Even a single episode of hyperglycemia has been associated with increased LOS, twofold increase in reoperation, and 10-fold increase in 30-day mortality in patients without diabetes. ${ }^{32}$ Without adequate testing, many episodes of hyperglycemia are likely unrecognized and therefore untreated in our setting. Given prevalence of postoperative hyperglycemia in patients without diabetes in our study and in other settings, the utility of POCT in patients without diabetes should be an area of future study.

More than a quarter of patients with diabetes and more than half of patients without known diabetes who had hyperglycemia did not receive insulin, including $10 \%$ of patients with diabetes who had blood glucose greater than $18.0 \mathrm{mmol} / \mathrm{L}$. In addition, we found that most patients with hyperglycemia were treated with sliding scale-only regimens rather than the recommended basal bolus insulin regimens, advocated by Diabetes Canada based on high-quality evidence. ${ }^{25}$ This is considerably greater than the $24 \%$ of patients with diabetes who had 'inappropriate' postoperative management of diabetes reported in other studies. ${ }^{15}$ The landmark RABBIT-2 trial (Randomized Study of Basal-Bolus Insulin Therapy in the Inpatient Management of Patients With Type 2 Diabetes 2 trial) randomized patients undergoing surgery to sliding scale insulin or basal bolus insulin regimens, and found that patients who were prescribed basal bolus regimens had improved glycemic control and fewer in-hospital complications. ${ }^{38}$ Barriers to use of basal bolus insulin regimens have been previously identified and include fears of hypoglycemia, lack of skills to prescribe these regimens by surgical team members, and clinical inertia. ${ }^{13} 16$ Evidence-informed knowledge translation strategies to increase use of basal bolus insulin regimens for postoperative patients with hyperglycemia are needed.

Altogether, our results demonstrate a quality gap for patients with and without diabetes undergoing surgery that is associated with worse clinical outcomes, including hyperglycemia and longer LOS. Perioperative glycemic care pathways that protocolize preoperative screening for diabetes, postoperative measurement of glucose, and evidence-based treatment of postoperative hyperglycemia demonstrate reduced postoperative 
hyperglycemia. ${ }^{101129}$ Further, implementation of these pathways may also improve clinical outcomes, in particular surgical site infections. ${ }^{101129}$ With the burden of postoperative hyperglycemia and its association with worse clinical outcomes, multidisciplinary perioperative teams should consider implementation of standard POCT measurement protocols for patients with diabetes. Implementation of perioperative glycemic management pathways should be guided by theory and evidence to increase uptake and sustainability.

Our study has important limitations. Due to the low proportion of patients who underwent POCT for blood glucose, estimates of the prevalence of postoperative hyperglycemia and of the association between postoperative hyperglycemia and patient outcomes, including LOS, are limited. Therefore, the association between postoperative hyperglycemia in patients with and without diabetes and longer LOS should be considered exploratory. Despite this limitation, increased LOS for surgical patients with diabetes has been reported in multiple observational studies. ${ }^{13}$ In addition, while we included a variety of surgical disciplines, our result is from a single hospital and the generalizability of these results to other centers is unknown; however, data from other studies suggest that similar quality gaps for surgical patients with diabetes are common. ${ }^{15}$

This large, retrospective study of hospitalized surgical patients found that low proportions of patients with and without diabetes undergo preoperative HbA1c measurement and postoperative monitoring for hyperglycemia. The proportion of patients with postoperative hyperglycemia was high, and though this estimate of hyperglycemia is likely confounded by the indication for blood glucose measurement, it highlights a gap to optimize in this population. Patients with hyperglycemia more commonly received sliding scale insulin regimens rather than recommended basal bolus insulin regimens. Further, we found that patients with postoperative hyperglycemia had a longer LOS, regardless of a diagnosis of diabetes. Additional research is needed on the utility of preoperative $\mathrm{HbAlc}$ measurement and postoperative POCT for patients without diabetes. Overall, these results suggest knowledge translation and quality improvement work is needed to realize and reduce the burden of postoperative hyperglycemia in patients with and without diabetes undergoing surgery.

Contributors SMR and AC conceived this project, researched the data, wrote the manuscript and reviewed/edited the manuscript. TGH and EE researched the data, provided the statistical analysis, and reviewed/edited the manuscript. JM and $\mathrm{KH}$ assisted with conception of the project, researched the data, and reviewed/edited the manuscript. SMR is responsible for the overall content as the guarantor.

Funding This work was supported by a Cumming School of Medicine Department of Medicine Health Analytics Working Grant.

Competing interests None declared.

Patient consent for publication Not required.

Ethics approval This study was approved by the University of Calgary's Ethics Review Board (REB21-0089) and the need for individual participant consent was waived.
Provenance and peer review Not commissioned; externally peer reviewed.

Data availability statement Data are available upon reasonable request. Data are available from the corresponding author upon reasonable request. Data may be further deidentified prior to distribution as required by our institution.

Open access This is an open access article distributed in accordance with the Creative Commons Attribution Non Commercial (CC BY-NC 4.0) license, which permits others to distribute, remix, adapt, build upon this work non-commercially, and license their derivative works on different terms, provided the original work is properly cited, appropriate credit is given, any changes made indicated, and the use is non-commercial. See: http://creativecommons.org/licenses/by-nc/4.0/.

ORCID IDs

Shannon M Ruzycki http://orcid.org/0000-0002-8122-2910

Karmon Helmle http://orcid.org/0000-0001-5620-3104

\section{REFERENCES}

1 Guzman JZ, latridis JC, Skovrlj B, et al. Outcomes and complications of diabetes mellitus on patients undergoing degenerative lumbar spine surgery. Spine 2014;39:1596-604.

2 Jones CE, Graham LA, Morris MS, et al. Association between preoperative hemoglobin A1c levels, postoperative hyperglycemia, and readmissions following gastrointestinal surgery. JAMA Surg 2017:152:1031-8.

3 Kotagal M, Symons RG, Hirsch IB, et al. Perioperative hyperglycemia and risk of adverse events among patients with and without diabetes. Ann Surg 2015;261:97-103.

4 Punthakee Z, Iglesias PP, Alonso-Coello P, et al. Association of preoperative glucose concentration with myocardial injury and death after non-cardiac surgery (GlucoVISION): a prospective cohort study. Lancet Diabetes Endocrinol 2018;6:790-7.

5 Smiley DD, Umpierrez GE. Perioperative glucose control in the diabetic or nondiabetic patient. South Med J 2006;99:580-9.

6 van den Boom W, Schroeder RA, Manning MW, et al. Effect of A1c and glucose on postoperative mortality in noncardiac and cardiac surgeries. Diabetes Care 2018;41:782-8.

7 Murad MH, Coburn JA, Coto-Yglesias F, et al. Glycemic control in non-critically ill hospitalized patients: a systematic review and metaanalysis. J Clin Endocrinol Metab 2012;97:49-58.

8 Bock M, Johansson T, Fritsch G, et al. The impact of preoperative testing for blood glucose concentration and haemoglobin A1c on mortality, changes in management and complications in noncardiac elective surgery: a systematic review. Eur J Anaesthesiol 2015;32:152-9.

9 Capozzi JD, Lepkowsky ER, Callari MM, et al. The prevalence of diabetes mellitus and routine hemoglobin A1c screening in elective total joint arthroplasty patients. J Arthroplasty 2017;32:304-8.

10 Al-Niaimi AN, Ahmed M, Burish N, et al. Intensive postoperative glucose control reduces the surgical site infection rates in gynecologic oncology patients. Gynecol Oncol 2015;136:71-6.

11 Hopkins L, Brown-Broderick J, Hearn J, et al. Implementation of a referral to discharge glycemic control initiative for reduction of surgical site infections in gynecologic oncology patients. Gynecol Oncol 2017;146:228-33.

12 Helmle KE, Dechant AL, Edwards AL. Implementation of a multidisciplinary educational strategy promoting Basal-Bolus insulin therapy improves glycemic control and reduces length of stay for inpatients with diabetes. Clin Diabetes 2019;37:82-5.

13 Helmle KE, Edwards AL, Kushniruk AW, et al. Qualitative evaluation of the barriers and facilitators influencing the use of an electronic basal bolus insulin therapy protocol to improve the care of adult inpatients with diabetes. Can J Diabetes 2018;42:459-64.

14 Ruzycki SM, Harrison T, Cameron A, et al. Perioperative glycemic management for patients with and without diabetes. Canadian Journal of General Internal Medicine 2021;16:17-23.

15 Death NCEiPOa. Perioperative diabetes: highs and Lows. NCEPOD. Death NCEiPOa, 2018.

16 Flemons K, Bosch M, Coakeley S. Barriers and facilitators of following perioperative internal medicine recommendations by surgical teams: a sequential, explantory mixed-methods study. Preprint 2020.

17 Shah M, Apsey HA, Stearns JD, et al. Guidelines to improve perioperative management of diabetes mellitus: an example of a successful quality initiative. Diabetes Manag 2014;4:327-37.

18 Improvement IfH. Science of improvement: establishing measures IHI website: IHI, 2020.

19 Benchimol El, Smeeth L, Guttmann A, et al. The reporting of studies conducted using observational Routinely-collected health data (record) statement. PLoS Med 2015;12:e1001885. 
20 Adams AD, Benner RS, Riggs TW, et al. Use of the STROBE checklist to evaluate the reporting quality of observational research in obstetrics. Obstet Gynecol 2018;132:507-12.

21 Morabia A. Strobe for the International comparison of health determinants. Int J Public Health 2008;53:11-12.

22 Hux JE, Ivis F, Flintoft V, et al. Diabetes in Ontario: determination of prevalence and incidence using a validated administrative data algorithm. Diabetes Care 2002;25:512-6.

23 System NDS. Report from the National diabetes surveillance system: diabetes in Canada. Public health agency of Canada reports and publications, 2009.

24 Diabetes Canada Clinical Practice Guidelines Expert Committee, Punthakee Z, Goldenberg R, et al. Definition, classification and diagnosis of diabetes, prediabetes and metabolic syndrome. Can J Diabetes 2018;42 Suppl 1:S10-15.

25 Malcolm J, Halperin I, Miller DB. Diabetes Canada guidelines: inhospital management of diabetes. Can J Diabetes 2018;42.

26 Canadian Diabetes Association Clinical Practice Guidelines Expert Committee, Houlden R, Capes S, et al. In-Hospital management of diabetes. Can J Diabetes 2013;37 Suppl 1:S77-81.

27 Group PMoPwDMCKTW. Perioperative management of patients with diabetes mellitus. Alberta Health Services, 2019.

28 Coan KE, Schlinkert AB, Beck BR, et al. Perioperative management of patients with diabetes undergoing ambulatory elective surgery. $J$ Diabetes Sci Technol 2013;7:983-9.

29 Thompson BM, Stearns JD, Apsey HA, et al. Perioperative management of patients with diabetes and hyperglycemia undergoing elective surgery. Curr Diab Rep 2016;16:2.
30 Dhatariya K, Levy N, Kilvert A, et al. Nhs diabetes guideline for the perioperative management of the adult patient with diabetes. Diabet Med 2012;29:420-33.

31 Ekinci El, Kong A, Churilov L, et al. Using automated $\mathrm{HbA} 1 \mathrm{c}$ testing to detect diabetes mellitus in orthopedic inpatients and its effect on outcomes. PLoS One 2017;12:e0168471.

32 Kiran RP, Turina M, Hammel J, et al. The clinical significance of an elevated postoperative glucose value in nondiabetic patients after colorectal surgery: evidence for the need for tight glucose control? Ann Surg 2013;258:599-604.

33 Diabetes Canada Clinical Practice Guidelines Expert Committee, Ekoe J-M, Goldenberg R, et al. Screening for diabetes in adults. Can J Diabetes 2018;42 Suppl 1:S16-19.

34 Hommel I, van Gurp PJ, Tack CJ, et al. Major gaps between recommended perioperative diabetes care and current practice. Eur J Intern Med 2016;34:e11-13.

35 Polderman JAW, Hollmann MW, DeVries JH, et al. Perioperative hyperglycemia and glucose variability in gynecologic laparotomies. $J$ Diabetes Sci Technol 2015;10:145-50.

$36 \mathrm{Hu} \mathrm{Q}$, Ren J, Li G, et al. Clinical significance of post-operative hyperglycemia in nondiabetic patients undergoing definitive surgery for gastrointestinal fistula. Surg Infect 2016;17:491-7.

37 Yang $\mathrm{MH}$, Jaeger $\mathrm{M}$, Baxter $\mathrm{M}$, et al. Postoperative dysglycemia in elective non-diabetic surgical patients: a prospective observational study. Can J Anaesth 2016;63:1319-34.

38 Umpierrez GE, Smiley D, Jacobs S, et al. Randomized study of basal-bolus insulin therapy in the inpatient management of patients with type 2 diabetes undergoing general surgery (rabbit 2 surgery). Diabetes Care 2011;34:256-61. 